\title{
Comparative evaluation of different doses of ciprofloxacin alone and in combination with sulfasalazine in experimentally induced inflammatory bowel disease in rats
}

\author{
Shivashankar Parashuram ${ }^{1}$, Purushotham Krishna ${ }^{2}$, Mangala Lahkar ${ }^{1}$
}

\begin{abstract}
${ }^{1}$ Department of Pharmacology, Gauhati Medical College and Hospital, Guwahati, India, ${ }^{2}$ Department of Pharmacology, Sri Siddhartha Medical College, Tumakuru, India
\end{abstract}

Received: 12 June 2016

Accepted: 04 July 2016

\section{*Correspondence to:}

Dr. Purushotham Krishna, Email: dr.arian18@gmail.com

Copyright: (c) the author(s), publisher and licensee Medip Academy. This is an openaccess article distributed under the terms of the Creative Commons Attribution NonCommercial License, which permits unrestricted noncommercial use, distribution, and reproduction in any medium, provided the original work is properly cited.

\begin{abstract}
Background: Inflammatory bowel disease (IBD) is an idiopathic, chronic inflammatory condition, which affects the gastrointestinal tract and has no curative treatment. The present study aimed to investigate the effect of different doses of ciprofloxacin alone and in combination with sulfasalazine in AA (acetic acid)-induced inflammatory bowel disease (IBD) in rats.

Methods: A total of 36 animals were included in the study. Animals were divided into five groups $(n=6)$ : group I - control (normal saline), group II-AA+ normal saline, group III-sulfasalazine $(360 \mathrm{mg} / \mathrm{kg})+\mathrm{AA}$, group IV A ciprofloxacin $(50 \mathrm{mg} / \mathrm{kg})$, group IV B- ciprofloxacin $100 \mathrm{mg} / \mathrm{kg}+\mathrm{AA}$, group V - ciprofloxacin $100 \mathrm{mg} / \mathrm{kg}$ + sulfasalazine $(360 \mathrm{mg} / \mathrm{kg})+\mathrm{AA}$. Group IV was divided into two subgroups, namely IVA and IVB, on the basis of different doses of ciprofloxacin used. After completion of two weeks of treatment, rats were sacrificed under ether anaesthesia for assessment of intestinal inflammation using parameters namely colon weight change, macroscopic and histopathological evaluation.

Results: There was a decrease in colonic weight, macroscopic scores and microscopic scores in groups treated with ciprofloxacin at a dose of $100 \mathrm{mg} / \mathrm{kg}$ i.e. high dose given alone and in combination with sulfasalazine. Combination treatment was more effective when compared to single drug treatment.

Conclusions: The present study indicates the efficacy of ciprofloxacin in acetic acid-induced IBD. The effects are more pronounced at higher dose i.e., 100 $\mathrm{mg} / \mathrm{kg}$. Combination of ciprofloxacin and sulfasalazine has shown greater efficacy than single drug treatment.
\end{abstract}

Keywords: Inflammatory bowel disease, Ciprofloxacin, Colon weight change, macroscopic evaluation, histopathological evaluation

\section{INTRODUCTION}

Inflammatory bowel disease (IBD) is an immunemediated chronic intestinal condition. Ulcerative colitis (UC) and Crohn's disease (CD) are the two major types of IBD. The incidence of IBD, especially UC, is rising in Japan, South Korea, Singapore, northern India and Latin America, areas previously thought to have low incidence. ${ }^{1}$

Patients with CD and UC alternate between periods of active disease, which may require hospital admission, and periods of remission. The cause of IBD seems to include genetic, environmental, and immunologic components. Evidence suggests that IBD is triggered by an aberrant immune response to enteric flora, leading to intestinal inflammation. ${ }^{2,3}$

Pathophysiological changes in IBD are well established, among which cytokines like tumor necrosis factor $\alpha$ (TNF- $\alpha$ ), interleukin-1 (IL-1) and interleukin-8 (IL-8) are secreted from macrophages. ${ }^{4}$ TNF- $\alpha$ upregulates the adhesion molecules (E selectin and ICAM-1) causing the adherence of neutrophils in endothelium and passage into 
the bowel wall. Release of IL-8 attracts the activated neutrophils, and causes degranulation of the toxic proteases and other reactive oxygen species, which are cytotoxic and cause ulceration of intestine. ${ }^{4}$ Frontline drugs that are currently used to treat IBD includes 5aminosalicylic acid (sulfasalazine), corticosteroids (prednisolone), immunomodulatory drugs (azathioprine, mercaptopurine, methotrexate), IgG anti-TNF $\alpha$ antibody (infliximab) and antibiotics. ${ }^{5}$ These drugs have varying efficacy from patient to patient, and long-term use of these drugs can have harmful side effects. In view of the devastating nature of IBD and the limited efficacy of the drugs used for its treatment, it would be very helpful to have other effective anti-inflammatory drugs.

Fluoroquinolones are quinolone antimicrobials having one or more fluorine substitutions with extended activity not only to gram negative organisms but also to gram positive cocci and anaerobes. These agents inhibit DNA gyrase in gram negative and topoisomerase II in gram positive organisms. They are used in various infections involving urinary tract, respiratory tract, gastro intestinal tract, bone etc. Ciprofloxacin is used as a second line drug in treatment of tuberculosis. ${ }^{6}$

IBD is treated with ciprofloxacin and metronidazole. Few studies have shown an advantage of this regimen compared with other antibiotics. Most attributed the effect to its better antibacterial coverage. Others have shown an apparent anti-inflammatory effect of quinolones in several in vitro and in vivo models of inflammation other than IBD. ${ }^{7}$

With this background, the present study was conducted to evaluate the effect of different doses of ciprofloxacin alone and in combination with sulfasalazine in experimentally induced inflammatory bowel disease in rats.

\section{METHODS}

\section{Materials}

The present study was conducted in the department of pharmacology, Gauhati Medical College, Guwahati. The anti-inflammatory effect of rosiglitazone alone and in combination with sulfasalazine was studied in experimentally induced inflammatory bowel disease in albino rats.

\section{Experimental animals}

Adult wistar albino rats of either sex weighing between 150-250 gm were procured from the institute central animal house. The animals were housed in standard laboratory conditions at $250^{\circ} \mathrm{C}$ and 12 hours light and dark cycle. Animals were given free access to rat chow diet and water ad libitum. Before conducting experiments animals were acclimatized to laboratory conditions for seven days.

\section{Drugs and chemicals}

Drugs and chemicals needed for the study are sulfasalazine (Cadila), acetic acid (AA) and ciprofloxacin (Cipla).

Experimental protocol was approved by the institutional animal ethics committee (IAEC) of Gauhati Medical College, Guwahati (IAEC No: 351/CPCSEA/3/1/2001). The study was performed in accordance to the CPCSEA guidelines.

\section{Dose and route of administration}

- $\quad$ Sulfasalazine - $360 \mathrm{mg} / \mathrm{kg}$ per oral (P.O $)^{8}$

- Ciprofloxacin - $50 \mathrm{mg} / \mathrm{kg}$ and $100 \mathrm{mg} / \mathrm{kg}$ (P.O) ${ }^{9}$

- $\quad$ Acetic acid - $1 \mathrm{ml}$ of $4 \%$ transrectally (T.R)

Total 36 animals were included in the study. Animals were divided into five groups I, II, III, IV and V. Group IV was subdivided into two subgroups A and B. Each group and subgroup will have six animals.

\section{Groups were}

- Group I control group

- Group II acetic acid treated group

- Group III positive control group - sulfasalazine (360 $\mathrm{mg} / \mathrm{kg})+4 \%$ AA

- Group IV test group (ciprofloxacin + AA)

- Group IV sub group A - ciprofloxacin $(50 \mathrm{mg} / \mathrm{kg})+$ $4 \%$ AA

- Group IV sub group B - ciprofloxacin (100 mg/kg) + $4 \%$ AA

- Group V - sulfasalazine $(360 \mathrm{mg} / \mathrm{kg})+$ ciprofloxacin $(50 \mathrm{mg} / \mathrm{kg})+4 \% \mathrm{AA}$

\section{Induction of colitis}

IBD was induced according to the procedure described by MacPherson and Pfeiffer. ${ }^{10}$ Briefly, rats were slightly anaesthetized with ether following 24 hours fast, a soft $6 \mathrm{~F}$ paediatric catheter lubricated with lignocaine jelly was inserted rectally into the colon through anus such that tip is $8 \mathrm{~cm}$ proximal to anus, approximately at the splenic flexure. Then $1 \mathrm{ml} 4 \%$ acetic acid was introduced into the colon and, after $30 \mathrm{~s}$ of exposure, the fluid was withdrawn. As previously shown, an intra-rectal administration of $4 \%$ acetic acid produces colonic inflammation in rats that resembles many histological characteristics of human ulcerative colitis. ${ }^{11}$

The experimental animals were divided into mainly 5 groups.

Group I: (Normal saline treated group) in this group $1 \mathrm{ml}$ of normal saline was delivered intra-rectally to the rats after ether anaesthesia as method described earlier. 
Group II: (Acetic acid treated group) $1 \mathrm{ml}$ of $4 \%$ acetic acid was delivered intra-rectally to the rats after ether anaesthesia as mentioned earlier to induce colitis.

Group III: (Sulfasalazine treated group) rats received sulfasalazine $360 \mathrm{mg} / \mathrm{kg}$ of rat body weight, orally daily by intra-gastric tube for 7 days. On 7 th day, $1 \mathrm{hr}$ after sulfasalazine administration rats was given $1 \mathrm{ml}$ of $4 \%$ acetic acid intra-rectally after ether anaesthesia.

Group IV: (Ciprofloxacin treated group) animals were divided into two subgroups on the basis of different doses. Total 12 rats were included in this group. Each group had six animals.

Group IV sub group A: Ciprofloxacin in the dose of 50 $\mathrm{mg} / \mathrm{kg}$ body weight of rat was given orally once daily by intra-gastric tube for 7 days. On the $7^{\text {th }}$ day, 1 hour after Ciprofloxacin administration rats was given $1 \mathrm{ml}$ of $4 \%$ acetic acid intra-rectally after ether anaesthesia.

Group IV sub group B: Ciprofloxacin in the dose of 100 $\mathrm{mg} / \mathrm{kg}$ body weight of rat was given orally once daily by intra-gastric tube for 7 days. On the 7 th day, 1 hour after Ciprofloxacin administration rats was given $1 \mathrm{ml}$ of $4 \%$ acetic acid intra-rectally after ether anaesthesia.

Group V (Sulfasalazine and ciprofloxacin combination treated group) rats received combination of sulfasalazine $360 \mathrm{mg} / \mathrm{kg}$ body weight of rat orally daily with Ciprofloxacin $100 \mathrm{mg} / \mathrm{kg}$ (most effective dose found in group IV), orally once daily by intra-gastric tube for 7 days. On 7 th day, 1 hour after combination treatment, rats received $1 \mathrm{ml}$ of $4 \%$ acetic acid intra-rectally after ether anaesthesia.

\section{Assessment of colonic damage}

The parameters assessed were colon weight change, macroscopic evaluation and histopathological evaluation and given macroscopic and microscopic score. The assessment was carried out in the department of pathology, Gauhati Medical College and Hospital.

\section{Colon weight change}

The weight of damaged colon tissue is considered an indicator of the severity and extent of inflammatory response, where an increase in colonic weight represents inflammation and a decrease in colonic weight following treatment indicates anti-inflammatory activity.

\section{Macroscopic evaluation}

Twenty-four hours following induction of colitis, animals were euthanized by ether and $10 \mathrm{~cm}$ of distal colon was removed from surrounding tissues, opened longitudinally along its mesenteric border, rinsed, and processed for histology. After washing the mucosa with saline solution, mucosal injury (macroscopically) was assessed using the grading scale of Morris et al. ${ }^{12}$

- $\quad$ Score 0 - No damage

- Score 1 - localized hyperemia but no ulcers

- Score 2 - linear ulcers with no significant inflammation

- Score 3 - linear ulcer with inflammation at one site

- Score 4 - two or more sites of ulceration and inflammation

- Score 5 - two or more sites of ulceration and inflammation or one major site of

Inflammation and ulceration extending $>1 \mathrm{~cm}$ along the length of the colon.

\section{Histopathological evaluation}

Additional samples were fixed in $10 \%$ formalin in phosphate buffered saline, embedded in paraffin, and cut into $4 \mu \mathrm{m}$ sections. Paraffin sections were deparaffinised with xylene, hydrated, and stained with haematoxylin and eosin. The degree of inflammation was graded semi quantitatively from 0 to 11 as the sum of: 13

- Loss of mucosal architecture (score 0-3)

- Cellular infiltration (score 0-3)

- Muscle thickening (score 0-3)

- Crypt abscess formation (score 0-1)

- Goblet cell depletion (score 0-1).

\section{Statistical analysis}

All the data were entered in to data base program. Data were expressed as mean \pm SEM. Results were analysed by one way analysis of variance (ANOVA), followed by Dunnet's multiple comparison test. $\mathrm{P}$ value $<0.05$ was considered as statistically significant.

\section{RESULTS}

\section{Colon weight changes (Table 1, Figure 1A)}

Mean colonic weight of group I was $4.38 \pm 0.18$ which is statistically significant ( $p<0.01$ ) when compared to group II with a mean colonic weight of $9.67 \pm 0.22$. Mean colonic weight of group III was $4.74 \pm 0.08$ which is statistically significant $(p<0.01)$ when compared with group II. In case of animals pre-treated with ciprofloxacin at a dose of $100 \mathrm{mg} / \mathrm{kg}$ (group IV B), mean colonic weight was $6.95 \pm 0.11$ which is statistically significant $(\mathrm{p}<0.05)$ when compared to the group II. But animals pre-treated with ciprofloxacin at a dose of $50 \mathrm{mg} / \mathrm{kg}$ (group IV A), mean colonic weight was $8.95 \pm 0.09$, which when compared to group II is statistically not significant ( $p>0.05)$. Whereas in animals pre-treated with combination of sulfasalazine with ciprofloxacin $100 \mathrm{mg} / \mathrm{kg}$ (group V), mean colonic weight was $5.6 \pm 0.19$ which is statistically significant compared with the group II $(\mathrm{p}<0.01)$. 
Table 1: Parameters for assessment of colonic inflammation.

\begin{tabular}{|lllll|} 
Groups & Treatment & $\begin{array}{l}\text { Colon weight } \\
\text { change }(\mathrm{gm})\end{array}$ & $\begin{array}{l}\text { Macroscopic } \\
\text { score }\end{array}$ & $\begin{array}{l}\text { Microscopic } \\
\text { score }\end{array}$ \\
\hline I & Normal saline & $4.38 \pm 0.18^{*}$ & $0.33 \pm 0.21^{*}$ & $0.41 \pm 0.16^{*}$ \\
\hline II & AA treated & $9.67 \pm 0.22$ & $4.83 \pm 0.17$ & $9.78 \pm 0.50$ \\
\hline III & Sulfasalazine+AA & $4.74 \pm 0.08^{*}$ & $1.67 \pm 0.21^{*}$ & $1.63 \pm 0.42^{*}$ \\
\hline IV A & Ciprofloxacin $(50 \mathrm{mg} / \mathrm{kg})+\mathrm{AA}$ & $8.95 \pm 0.09^{+}$ & $4.33 \pm 0.21^{+}$ & $6.76 \pm 0.93^{+}$ \\
\hline IV B & Ciprofloxacin $(100 \mathrm{mg} / \mathrm{kg})+\mathrm{AA}$ & $6.95 \pm 0.11^{\#}$ & $3.67 \pm 0.22^{\#}$ & $5.35 \pm 0.39^{\#}$ \\
\hline V & Sulfasalazine+ciprofloxacin $(100 \mathrm{mg} / \mathrm{kg})+\mathrm{AA}$ & $5.6 \pm 0.19^{*}$ & $2 \pm 0.25^{*}$ & $2.90 \pm 0.75^{*}$ \\
\hline
\end{tabular}

Data are expressed as mean \pm SEM $(n=6)$ and analyzed using one way ANOVA followed by Dunnett's $t$ test. The statistical significance was considered as significant if $* \mathrm{p}<0.01, \# \mathrm{p}<0.05,+\mathrm{p}<0.05$ when compared with acetic acid group.

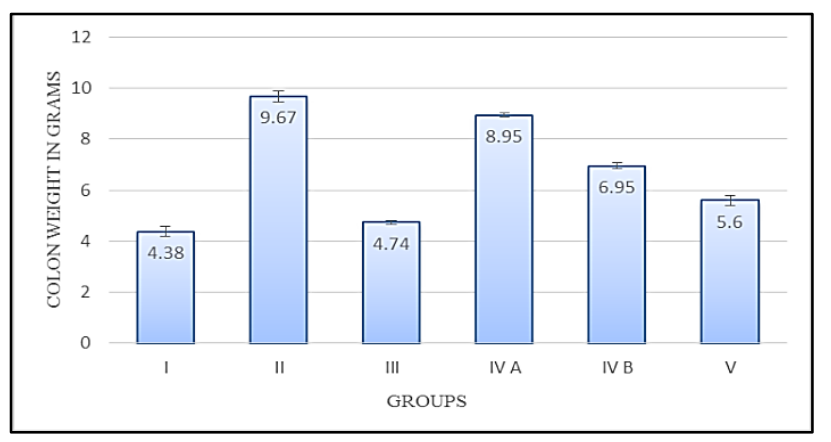

Figure 1 (A): Colon weight change (gm). Effect of different doses of ciprofloxacin alone and in combination with sulfasalazine on parameters of colonic inflammation in experimentally induced inflammatory bowel disease in rats.

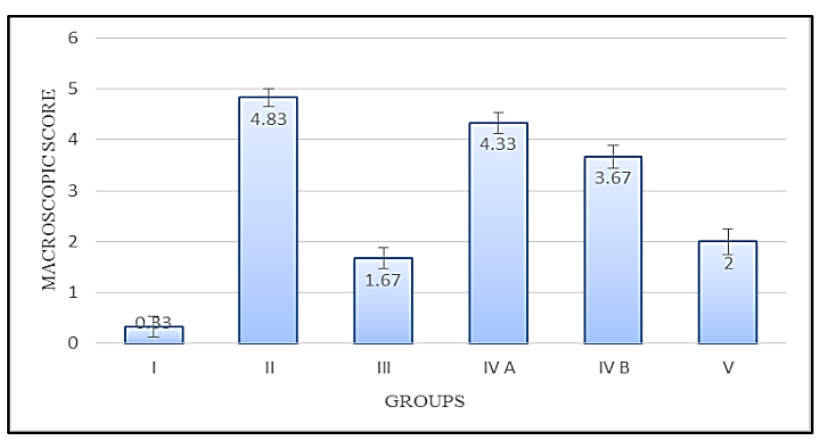

Figure 1 (B): Macroscopic evaluation.

\section{Macroscopic evaluation}

Mean values of macroscopic score of group I was $0.33 \pm 0.21$ (Table 1, Figure 1B) which is statistically significant $(\mathrm{p}<0.01)$ when to compared group II with a score of $4.83 \pm 0.16$. Mean macroscopic score of group III was $1.67 \pm 0.21$ which is statistically significant $(\mathrm{p}<0.01)$ when compared with group II. In case of animals pretreated with ciprofloxacin at a dose of $100 \mathrm{mg} / \mathrm{kg}$ (group IV B), mean macroscopic scoring was $3.67 \pm 0.22$ which is statistically significant $(\mathrm{p}<0.05)$ when compared to the group II. But animals pre-treated with ciprofloxacin at a dose of $50 \mathrm{mg} / \mathrm{kg}$ (group IV A), mean macroscopic score was $4.33 \pm 0.21$, which when compared to group II is statistically not significant ( $\mathrm{p}>0.05)$. Whereas in animals pre-treated with combination of sulfasalazine with ciprofloxacin $100 \mathrm{mg} / \mathrm{kg}$ (group V), mean macroscopic score was $2 \pm 0.25$ which is statistically significant compared with the group II ( $\mathrm{p}<0.01)$ (Figure 2).

\section{Histopathological evaluation}

Mean values of microscopic score of group I was $0.41 \pm 0.16$ (Table 1, Figure 1C) which is statistically significant $(\mathrm{p}<0.01)$ when compared to group II with a score of $9.78 \pm 0.50$. Mean microscopic score of group III was $1.63 \pm 0.42$ which is statistically significant $(\mathrm{p}<0.01)$ when compared with group II. In case of animals pretreated with ciprofloxacin at a dose of $100 \mathrm{mg} / \mathrm{kg}$ (group IV B), mean microscopic scoring was $5.35 \pm 0.39$ which is statistically significant $(\mathrm{p}<0.05)$ when compared to the group II. But animals pre-treated with ciprofloxacin at a dose of $50 \mathrm{mg} / \mathrm{kg}$ (group IV A), mean microscopic score was 6.76 \pm 0.93 , which when compared to group II is statistically not significant $(\mathrm{p}>0.05)$. Whereas in animals pre-treated with combination of sulfasalazine with ciprofloxacin $100 \mathrm{mg} / \mathrm{kg}$ (group V), mean microscopic score was $2.90 \pm 0.75$ which is statistically significant compared with the group II ( $\mathrm{p}<0.01)$.

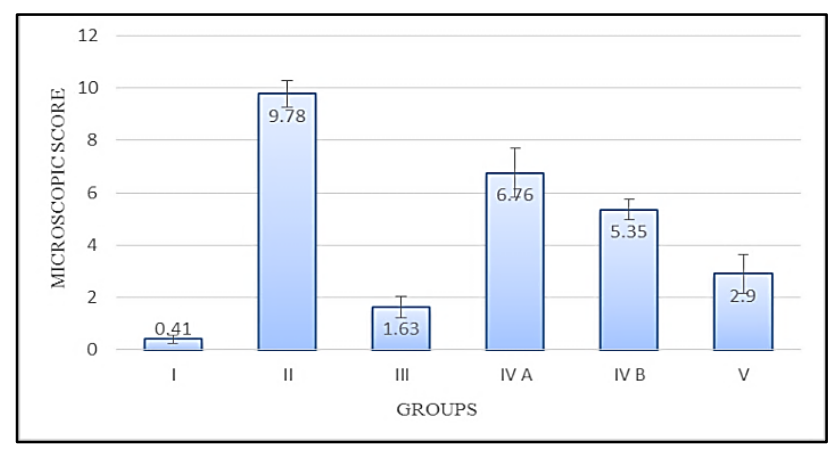

Figure 1 (C): Histopathological evaluation.

Thus from the above results, it is seen that ciprofloxacin at a dose of $100 \mathrm{mg} / \mathrm{kg}$ i.e. high dose given alone and in combination with sulfasalazine reduced colon weight and decreased macroscopic and microscopic score 
significantly. Combination treatment was more effective in decreasing microscopic damage score when compared to single drug treatment. Both combination treatment group and single drug treatment group were equally or less effective in decreasing microscopic damage score when compared with standard drug sulfasalazine (Figure 2).

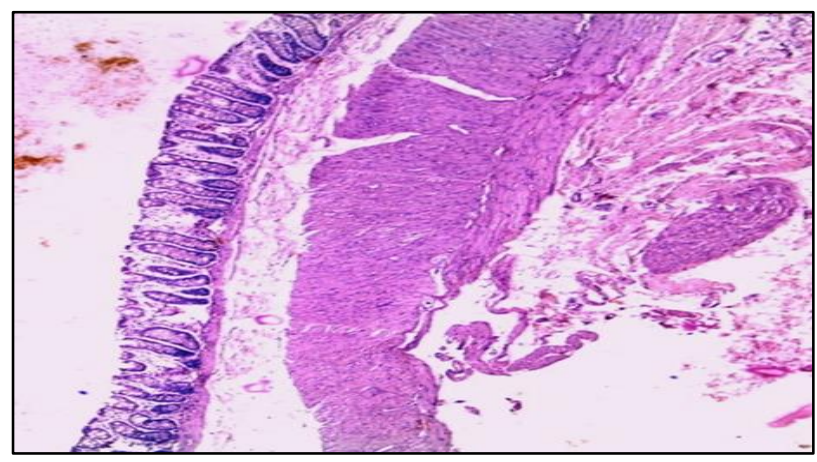

Figure 2 (A): Histopathological sections of colons from rats stained with $\mathrm{H}$ and $\mathrm{E}$. Colonic microscopic image of normal rat colon from control group I with intact mucosal layer and epithelial.

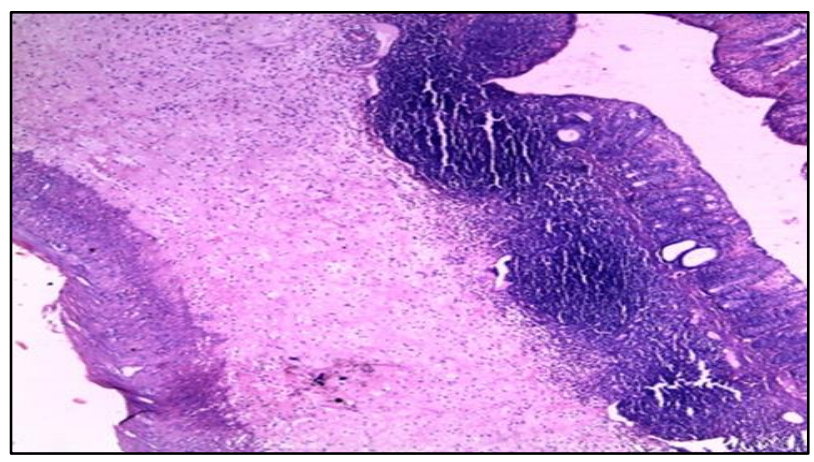

Figure 2 (B): AA treated (group II) rat colon with diffused active colitis, extensive damage including edema of mucosa and submucosa and chronic inflammatory cells infiltrate with widely ulcerating mucosa, and haemorrhages.

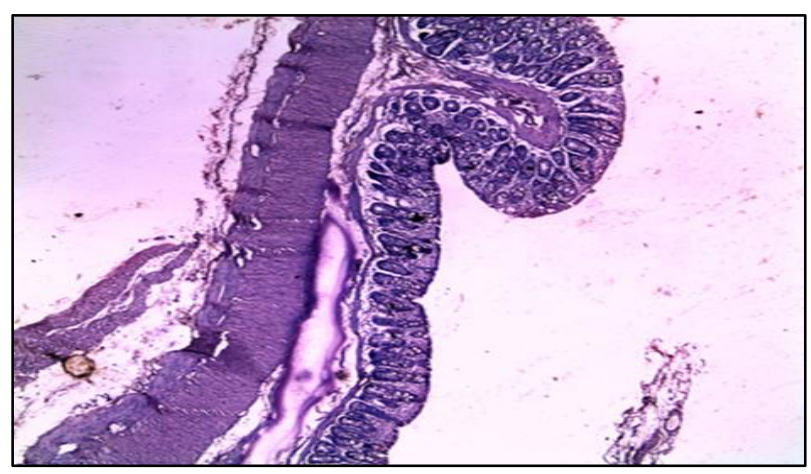

Figure 2 (C): Sulfasalazine treated (group III) colon with reduced active colitis, reduced mucosal ulcer and minimal inflammatory cell infiltrates.

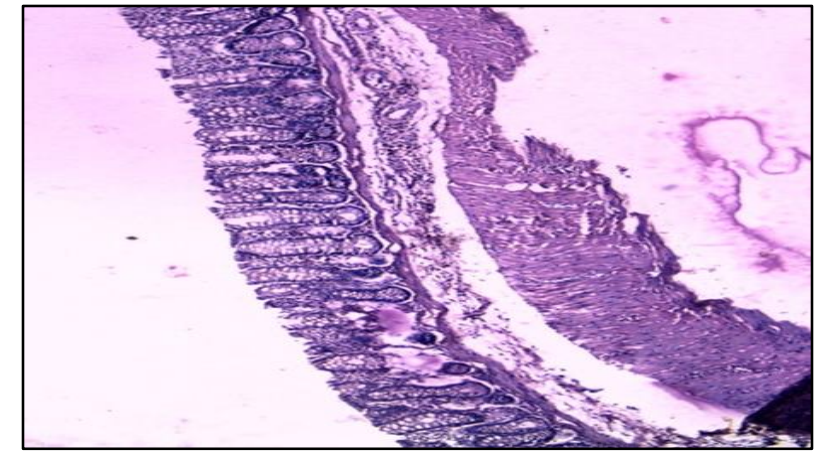

Figure 2 (D): Ciprofloxacin $100 \mathrm{mg} / \mathrm{kg}$ (group IV B) treated colon showing reparative epithelial changes and ulcer healing with lymphoid follicle in colon.

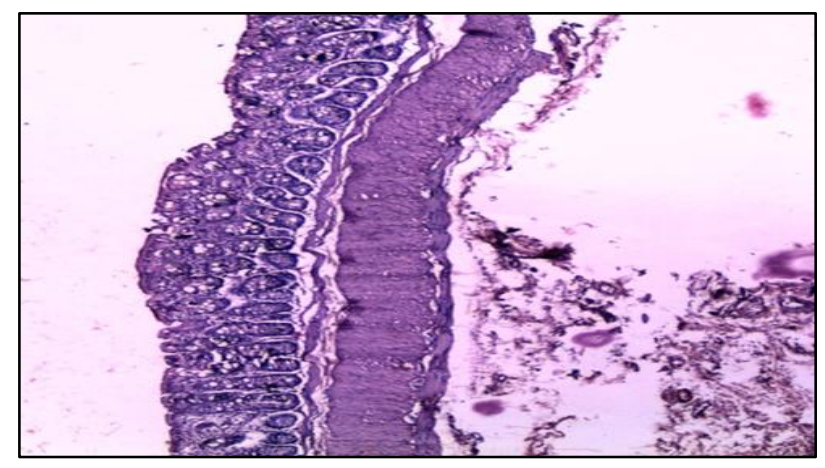

Figure 2 (E): Attenuated cell damage with minimal cell infiltrates and improved ulcer healing in group

treated with combination of sulfasalazine and ciprofloxacin $100 \mathrm{mg} / \mathrm{kg}$ (group V).

\section{DISCUSSION}

Inflammatory bowel diseases (IBD) including ulcerative colitis (UC) and Crohn's disease (CD) are amongst the most challenging human illness in the world. Inflammatory mediators such as cytokines, eicosanoids and reactive oxygen metabolites play a crucial role in the development and persistence of this disease.

Ciprofloxacin has been implicated in the control of inflammatory process in several in vitro and in vivo models of inflammation other than IBD. Thus the present study was carried out with an attempt to evaluate the antiinflammatory effect of ciprofloxacin alone and in combination with sulfasalazine in acetic acid induced inflammatory bowel disease in albino rats.

Induction of colitis in rats using acetic acid is a classical method used to produce an experimental model of human IBD. Several major causative factors in the initiation of human colitis such as enhanced vasopermeability, prolonged neutrophils infiltration, and increased production of inflammatory mediators are involved in the induction of this animal model. ${ }^{14}$ Acetic acid affects the distal colon portion and induces non-transmural inflammation, massive necrosis of mucosal and sub 
mucosal layers, mucosal edema, neutrophil infiltration of the mucosa and sub mucosal ulceration. The protonated form of the acid liberates protons within the intracellular space and causes a massive intracellular acidification resulting in massive epithelial damage. The inflammatory response initiated by acetic acid includes activation of cyclooxygenase and lipoxygenase pathways. ${ }^{15}$

Ciprofloxacin was given in the dose of $50 \mathrm{mg} / \mathrm{kg}$ and 100 $\mathrm{mg} / \mathrm{kg}$ body weight by gastric lavage. The standard drug sulfasalazine was given in the dose of $360 \mathrm{mg} / \mathrm{kg}$ body weight by gastric lavage and colitis was induced by giving $1 \mathrm{ml}$ of $4 \%$ acetic acid intra-rectally.

The parameters assessed were colon weight change, macroscopic evaluation and histopathological evaluation and given macroscopic and microscopic score. The weight of damaged colon tissue is considered an indicator of the severity and extent of inflammatory response. The effect of the drugs on colonic weight following acetic acid induced colitis was determined, where an increase in colonic weight represents inflammation and decrease in colonic weight indicates anti-inflammatory activity. There was a decrease in colonic weight in groups treated with ciprofloxacin at a dose of $100 \mathrm{mg} / \mathrm{kg}$ i.e. high dose given alone and in combination with sulfasalazine .The macroscopic scores and microscopic score were less in groups treated with ciprofloxacin at a dose of $100 \mathrm{mg} / \mathrm{kg}$ i.e. high dose given alone and in combination with sulfasalazine. Combination treatment was more effective in decreasing colon weight, macroscopic and microscopic score when compared to single drug treatment. Both combination treated group and single drug treated group when compared with standard drug sulfasalazine were equally or less effective.

A study by Lahat $\mathrm{G}$ et al, has demonstrated immunomodulatory effect of ciprofloxacin in TNBSinduced colitis in mice by decreasing microscopic and macroscopic score along with decrease in the expression of NF-kB and IL-1 $\beta$ recruiting neutrophils, which plays an important role in the pathogenesis of inflammatory bowel disease. ${ }^{16}$ Thus our study correlates well with the study by Lahat $\mathrm{G}$ et al, which showed decrease in colon weight, macroscopic and microscopic scoring.

A study by Rath $\mathrm{HC}$ et al which reported decreases in colon weight, macroscopic and microscopic mucosal damage score after ciprofloxacin administration as it targets TNF- $\alpha$ in addition to its antibacterial activity. ${ }^{17}$ This is well in correlation with our study where we found significant improvement in macroscopic and microscopic scoring.

Another study by Kilic FS has shown anti-inflammatory response of ciprofloxacin in formalin-induced edema in rats. ${ }^{18}$ The anti-inflammatory effect of ciprofloxacin was also evaluated on gastric mucus secretion by using alcian blue dye binding method. Anti-inflammatory effects of ciprofloxacin on the IL-8 synthesis in S. Aureus Newman driven nasal inflammation in vitro has been demonstrated by Sachse F et al. ${ }^{19}$ Thus from above study it is seen that ciprofloxacin has anti-inflammatory effect along with antibacterial effect by different mechanism.

Remund $\mathrm{K}$ et al has shown that ciprofloxacin attenuates airway obliteration after tracheal transplantation and that this effect may be based on the modulation of the TH1/TH2-balance by this antibiotic drug. ${ }^{20}$ As already described imbalance in the $\mathrm{TH} 1 / \mathrm{TH} 2$ parameters play a role in the development of IBD. This may be another mechanism by which ciprofloxacin has shown antiinflammatory activity in the present study.

Thus form the above discussion it is seen that ciprofloxacin at a dose of $100 \mathrm{mg} / \mathrm{kg}$ has significant antiinflammatory effect. Ciprofloxacin (100 mg/kg) when combined with sulfasalazine, a reference standard drug has shown to improve colonic mucosal damage significantly. And also from the above discussion it can be seen that ciprofloxacin has anti-inflammatory effect in colonic mucosa by more than one mechanism.

\section{CONCLUSION}

The present study indicates the anti-inflammatory activity of Ciprofloxacin in Acetic acid-induced IBD. The effects are more pronounced at higher dose i.e., $100 \mathrm{mg} / \mathrm{kg}$. Combination of ciprofloxacin and sulfasalazine has shown greater efficacy than single drug treatment. These findings however need further confirmation in human studies before it is introduced into clinical practice for treatment of inflammatory bowel disease.

\section{ACKNOWLEDGEMENTS}

Authors would like to thanks the staffs of Department of Pharmacology and Department of Pathology, Gauhati Medical College and Hospital, Guwahati, for their help at various stages of the study.

Funding: No funding sources Conflict of interest: None declared

Ethical approval: The study was approved by the Institutional Ethics Committee

\section{REFERENCES}

1. Friedman S, Blumberg S. Inflammatory bowel disease. In: Kasper DL, Braunwald U, Fauci AS, Hauser SL, Longo DL, Jameson JL, editors. Harrison's Principles of Internal medicine, $18^{\text {th }} \mathrm{Ed}$, McGraw-Hill; 2012:1776-1788.

2. Podolsky DK. Inflammatory bowel disease. N Engl J Med. 2002;347:417-29.

3. Bouma G, Strober W. The immunological and genetic basis of inflammatory bowel disease. Nat Rev Immunol. 2003;3:521-31.

4. Palmer KR, Penman ID. Disease of the alimentary tracts and pancreas. In: Davidson's principle and 
practice of medicine, Eds. Haslett C, Chilvers ER, Hunter JAA, Boon NA, $18^{\text {th }}$ edn., Churchill Livingstone, UK; 1999:659-668.

5. Kenneth M, Mc Quid MD. Alimentary tract. In: Current Medical Diagnosis and Treatment. $42^{\text {nd }}$ edn., Eds. Tierney LM, Macphee SJ, Papadakis MA, McGraw Hill, Chicago; 2003:602-611.

6. Bruton LL, Lazo JS, Parker KL. Goodman and Gilman's The Pharmacologic Basis of Therapeutics. $12^{\text {th }}$ edition. New York: Mc Graw Hill Publishers; 2011.

7. Abraham C, Cho JH. Inflammatory bowel disease. $\mathrm{N}$ Engl J Med. 2009;361:2066-78.

8. Medhi B, Prakash A, Avti PK, Saikia UN, Pandhi P, Khanduja KL. Effect of manuka honey and sulfasalazine in combination to promote antioxidant defense system in experimentally induced ulcerative colitis model in rats. Indian Journal of Experimental Biology. 2008;46:583-90.

9. Kelly DE, Kaita, Assy N, Gauthier T, Zhang M, Adrienne FAM, et al. The beneficial effects of ciprofloxacin on survival and hepatic regenerative activity in a rat model of fulminant hepatic failure. Hepatology. 1998;27:2.

10. MacPherson BR, Pfeiffer CJ. Experimental production of diffuse colitis in rats. Digestion. 1978;17:135-50.

11. Choudhary S, Keshavarzian A, Yong S, Wade M, Bocckino S, Day BJ, et al. Novel antioxidants zolimid and AEOL11201 ameliorate colitis in rats. Dig Dis Sci. 2001;46:2222-30.

12. Morris GP, Beck PL, Herridge MS, Depew WT, Szewezuk MR, Wallace JL. Hapten-induced model of chronic inflammation and ulceration in the rat colon. Gastroenterology. 1989;96:795-803.

13. Weir RF. A new use for the useless appendix in surgical treatment of obstinate colitis. Med Rec. 1902;62:201.

14. Elson CO, Sartor RB, Tennyson GS, Riddell RH. Experimental models of inflammatory bowel disease. Gastroenterology. 1995;109:1344-67.

15. Nakhai LA, Mohammadirad A, Yasa N, Minaie B, Infer S, Ghazanfari $\mathrm{G}$, et al. Benefits of Zataria multiflora Boiss in experimental model of mouse inflammatory bowel disease. E CAM. 2007;4(1):4350 .

16. Lahat G, Halperin D, Barazovsky E, Shalit I, Rabau $\mathrm{M}$, Klausner J, et al. Immunomodulatory effects of ciprofloxacin in TNBS-induced mice. Inflamm Bowel Dis. 2007;13(5):557-65.

17. Rath HC, Schultz M, Freitag R, Dieleman LA, Li FL, Linde HJ, et al. Different subsets of enteric bacteria induce and perpetuate experimental colitis in rats and mice. Infect Immun. 2001;69:2277-85.

18. Kilic FS, Batu O, Yildirim E, Erol K, Deliorman S, Uyar R. Ciprofloxacin and pefloxacin suppress the inflammatory response in rats. Journal of Health Science. 2003;49(5):391-4.

19. Sachse F, Von Eiff C, Becker K, Rudack C. Antiinflammatory effects of ciprofloxacin in S. aureus Newman induced nasal inflammation in vitro. Journal of Inflammation. 2008;5:11.

20. Remund K, Rechsteiner T, Rentsch K, Vogt P, Russi EW, Boehler A. Attenuation of airway obliteration by ciprofloxacin in experimental post-transplant bronchiolitis obliterans. Transplantation. 2008;85(5):726-31.

Cite this article as: Parashuram $\mathrm{S}$, Krishna $\mathrm{P}$, Lahkar M. Comparative evaluation of different doses of ciprofloxacin alone and in combination with sulfasalazine in experimentally induced inflammatory bowel disease in rats. Int $\mathrm{J}$ Basic Clin Pharmacol 2016;5:1629-35. 